\title{
The Benefits of High Injection Pressure on Future Heavy Duty Engine Performance
}

\author{
Author, co-author (Do NOT enter this information. It will be pulled from participant tab in \\ MyTechZone) \\ Affiliation (Do NOT enter this information. It will be pulled from participant tab in MyTechZone)
}

\begin{abstract}
Diesel fuel injection pressures have increased steadily on heavy duty engines over the last twenty years and pressures as high as $300 \mathrm{MPa}$ are now possible. This was driven by the need to control toxic exhaust emissions, in particular particulate emissions using advanced in-cylinder combustion strategies. With the introduction of efficient aftertreatment systems for both particulate and $\mathrm{NO}_{\mathrm{x}}$ emissions control there is less demand for in-cylinder emissions control especially considering the drive for improved fuel economy. In this paper we consider the benefit of high fuel injection pressure for a number of emissions control strategies with different balances of in-cylinder and exhaust aftertreatment emissions control. A test program was undertaken on a single cylinder heavy duty research engine installed at the University of Brighton, in collaboration with Ricardo. The engine was fitted with the Delphi F2E fuel injection system capable of 330MPa injection pressure and multiple fuel injections. The engine intake system was configured to give independent control of the intake pressure and EGR rates, achieving rates of up to $50 \%$ at high engine loads. The benefit of high injection pressure was investigated under a number of strategies for achieving Euro VI emissions levels. The trade-off of controlling $\mathrm{NO}_{\mathrm{x}}$ emissions using EGR rate and aftertreatment on engine performance and Total Cost of Ownership (TCO) was investigated. Finally, the benefit of a simple split injection strategy at high rail pressure was studied.
\end{abstract}

\section{Introduction}

Commercial vehicle $\mathrm{NO}_{\mathrm{x}}$ emissions have reduced by over one order of magnitude since the introduction of emissions control legislation in the 1990's [1]. Up until recently, the majority of emissions control was achieved 'in-cylinder' using highly optimized combustion systems with cooled EGR and high pressure flexible Fuel Injection Equipment (FIE). As emissions legislation continued to reduce $\mathrm{NO}_{\mathrm{x}}$, and the required EGR rates consequently increased, the impact of achieving ultra-low $\mathrm{NO}_{\mathrm{x}}$ on both the engine architecture and fuel consumption became a concern. Post combustion $\mathrm{NO}_{\mathrm{x}}$ control through Selective Catalytic Reduction (SCR) was first introduced on commercial vehicles in 2005 (Euro IV) and was the preferred solution by 2010 combined with modest in-cylinder $\mathrm{NO}_{\mathrm{x}}$ control. The introduction of Euro VI in 2014 / 2015, required a very low $\mathrm{NO}_{\mathrm{x}}$ emission of $0.4 \mathrm{~g} / \mathrm{kWh}$ and a range of strategies with different balances of in-cylinder and aftertreatment strategies, have been adopted by the OEMs.

- Aftertreatment only strategy requiring high SCR efficiencies of $>95 \%$
- Hybrid 'light' EGR + SCR strategy requiring SCR efficiencies of $\sim 90 \%$

As will be shown in this paper, and by others [2,3], Euro VI $\mathrm{NO}_{\mathrm{x}}$ emissions can be achieved through in-cylinder means alone with only particulate aftertreatment, but this approach has not been adopted by vehicle manufactures to date due to the impact of such a strategy on the engine boost system and fuel consumption.

The evolution of emissions control measures and fuel injection pressure requirements are summarized in table 1 for various European emissions standards. Throughout this period, the pressure capability and flexibility of the fuel injection equipment have increased significantly. In the future, with pressure to reduce $\mathrm{CO}_{2}$ emissions a system solution combining advanced combustion and aftertreatment technology and waste heat recovery can be expected $[1,4,5]$. Advanced fuel injection systems can be expected to play a critical role in delivering high efficiency ultra low emissions combustion systems.

\begin{tabular}{|l|l|l|l|l|l|}
\hline $\begin{array}{l}\text { Emissions } \\
\text { Standard }\end{array}$ & Year & $\begin{array}{l}\text { NO }{ }_{\mathrm{x}} \text { Limit } \\
(\mathrm{g} / \mathrm{kWh})\end{array}$ & $\begin{array}{l}\text { Pm Limit } \\
(\mathrm{g} / \mathrm{kWh})\end{array}$ & $\begin{array}{l}\text { FIE } \\
\text { Pressure } \\
(\mathrm{MPa})\end{array}$ & NOx Control \\
\hline Euro I & 1990 & 8 & 0.36 & $\sim 80$ & No EGR \\
\hline Euro II & 1995 & 7 & 0.15 & $\sim 100$ & No EGR \\
\hline Euro III & 2000 & 5 & 0.16 & $160-180$ & Cooled EGR \\
\hline Euro IV & 2005 & 3.5 & 0.03 & $180-200$ & $\begin{array}{l}\text { Cooled EGR } \\
\text { (some SCR })\end{array}$ \\
\hline Euro V & 2010 & 2 & 0.03 & $180-200$ & $\begin{array}{l}\text { SCR preferred } \\
\text { solution }\end{array}$ \\
\hline Euro VI & 2015 & 0.4 & $\begin{array}{l}0.01[\mathrm{Pn}< \\
\left.60^{11}\right]\end{array}$ & $180-250$ & $\begin{array}{l}\text { EGR+SCR } \\
\text { strategies }\end{array}$ \\
\hline
\end{tabular}

Table 1: The Evolution of European emissions control standards and typical emissions control strategy

Pressures of 300MPa with as many as nine fuel injection events are now possible [6] opening opportunities for new combustion strategies. Previous researchers through optical studies have shown that the behavior of ultra-high pressure fuel spray up to $300 \mathrm{MPa}$ follows the behavior expected from research at lower injection pressures [7]. However, the benefit of high injection pressure on the emissions - fuel consumption and operating cost of a heavy duty engine is less clear. In this paper, we describe a program of research 
to investigate the benefit of ultra-high injection pressure on the emissions - fuel economy trade-off for different aftertreatment strategies. The research was undertaken on a Ricardo Proteus single cylinder research engine (SCRE) using the Delphi F2E injection system [8], with 330MPa injection pressures and multiple injection capability. The single cylinder engine, injection system and test facility are first described. Three design of experiment (DOE) test campaigns are then described representing different engine out $\mathrm{NO}_{\mathrm{x}}$ targets at mid load (A50) and high load (C100) conditions. Results from a short investigation into the benefits of split-injection are then described. The paper concludes with a discussion on the impact of the fuel injector capability on the optimal aftertreatment strategy and total system running costs (including Adblue consumption).

\section{Description of the Engine and Test Facility}

The program was undertaken using a Ricardo Proteus single cylinder engine (figure 1), installed at the University of Brighton. Key dimensions and characteristics of the engine are summarized in table 2. The combustion chamber was of the open chamber type, typical of heavy duty diesel systems.

\begin{tabular}{|l|l|}
\hline Bore & $131.1 \mathrm{~mm}$ \\
\hline Stroke & $150 \mathrm{~mm}$ \\
\hline Compression ratio & $16: 1$ \\
\hline Swept Volume & 2 litres \\
\hline Swirl & Quiescent \\
\hline Combustion Chamber & Open Chamber \\
\hline Diesel injection system & Delphi F2E Pumped Injector (330 MPa) \\
\hline
\end{tabular}

Table 2: Engine Characteristics

The engine was fitted with the Delphi F2E fuel injection system [8]. This injector is a hybrid pumped common rail type where a cam pressurizes a charge of fuel in the injector which is pumped to a common rail and then fuel is supplied from the rail during the firing stroke. The F2E was capable of delivering rail pressures of up to 330MPa during the current research and up to five individual injection events. The engine was instrumented with a Kistler 6152c cylinder pressure transducer captured on a high speed data logger. The drive current to the injector was also monitored to enable the injection timing to be precisely controlled.

Referring to figure 2, boost air was supplied from a separate air compressor via a pressure regulator. The exhaust back pressure was controlled to 1.1 times the inlet pressure via a butterfly valve. This ensures sufficient back pressure in the exhaust system to achieve the required EGR rates. It should be noted that at no EGR conditions it may not be necessary to operate this level of back pressure and so pumping losses may be reduced through careful matching of the turbocharger on a multi cylinder engine. EGR was introduced via a pipe connecting the exhaust and inlet. The EGR temperature was controlled by cooling part of the EGR flow and a valve was fitted to modulate the level of EGR. EGR rates were set by comparing the inlet and exhaust $\mathrm{CO}_{2}$ concentration. Intake charge temperature was regulated through control of intake air heater and EGR temperature.

Emissions data was captured using a Horiba 7170 emissions analyzer for gaseous emissions and an AVL 415s meter for particulate matter.

Page 2 of 8
The fuel flow to the engine was measured using an AVL733 fuel balance. Careful attention was made to controlling the fuel temperature to ensure the accuracy of the fuel consumption measurement. The program was undertaken using a standard Carcal RF0604B5 reference diesel fuel.

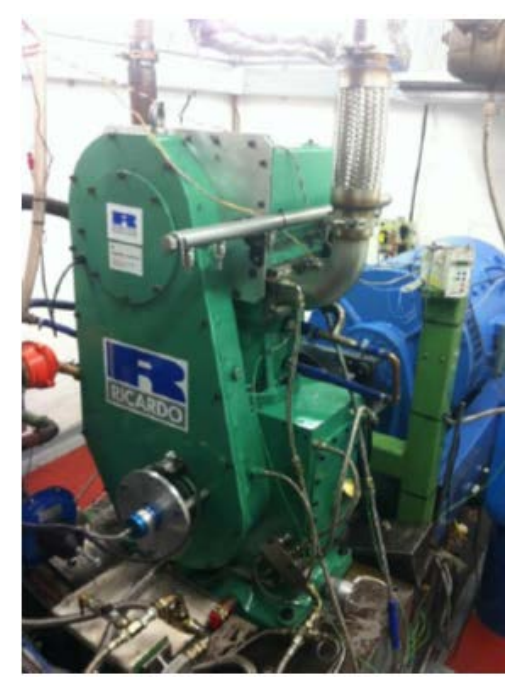

Figure 1: The Proteus single cylinder engine installed at the University of Brighton

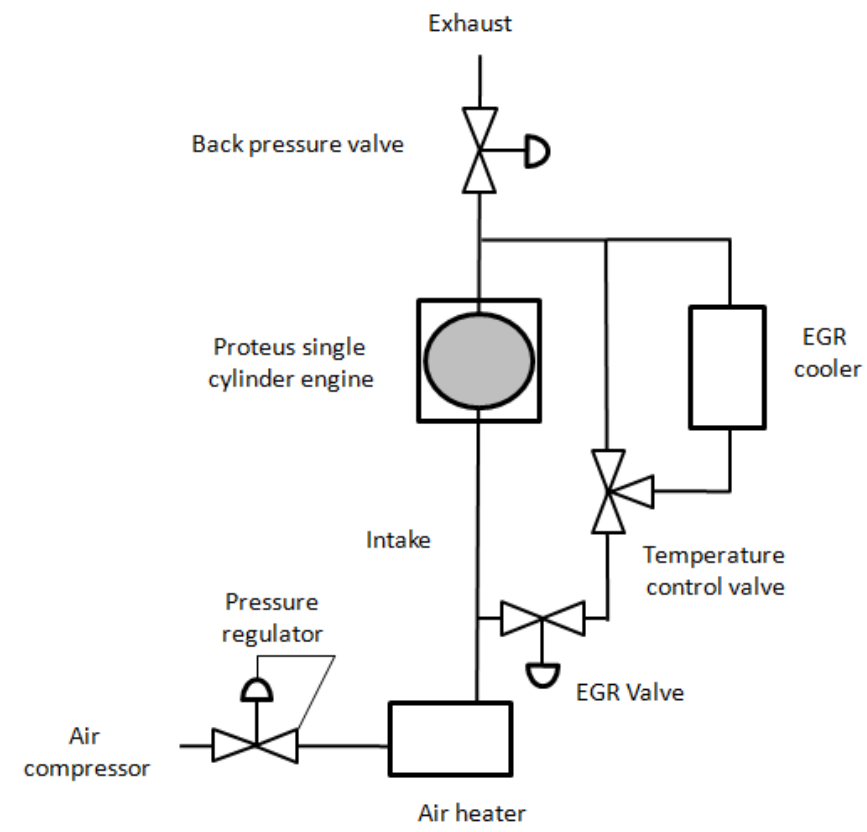

Figure 2: Diagram of intake and EGR System

\section{Test program}

Key points were defined to provide representative data for the calculation of fuel consumption and emissions performance across the legislated drive cycles and overall performance characteristics as follows: 
- $\quad$ A50 (1250rpm, 195Nm), representative of a cruise condition and high contribution to emissions on the WHTC and WHSC drive cycles

- $\quad$ C100 (1800rpm, 280Nm), representative of the rated power conditions where hardware limitations (Pmax, exhaust temperature, maximum fuel injection pressure) will often be reached so as to understand these constraints

The torque values selected for the single cylinder engine were scaled down from the levels observed on current 6 cylinder commercial heavy duty engines. The test program was undertaken using the Design of Experiments (DOE) method [9]. Test points were defined and the resulting models generated using the Ricardo Efficient Calibration software. The four inputs variables to the DOE were rail pressure, injection timing (defined as the start of the electronic pulse to the injector), boost pressure and EGR rate. Test sequences were defined at zero, moderate and high EGR levels, targeting $\mathrm{NO}_{\mathrm{x}}$ levels consistent with the three previously mentioned emissions control strategies. 50 test points were derived per test sequence making a total of circa 300 points. The following constraints were applied to the program to protect the engine and maintain the test points within realistic multi cylinder engine parameters:

- Maximum cylinder pressure

$22.5 \mathrm{MPa}$
$700^{\circ} \mathrm{C}$
$5 \mathrm{MPa}$ (abs)
$90^{\circ} \mathrm{C}$
$3 \mathrm{FSN}$ (at C100)
$330 \mathrm{MPa}$

- Maximum exhaust temperature

- Maximum boost pressure

- Maximum inlet pressure

- Maximum smoke

- Maximum rail pressure range of 150 to $180 \mathrm{MPa}$ is the optimal pressure for minimum fuel consumption. Effectively zero smoke emissions were observed above $2 \mathrm{~g} / \mathrm{kWhNO}$, below this value the smoke rose rapidly (figure 5).

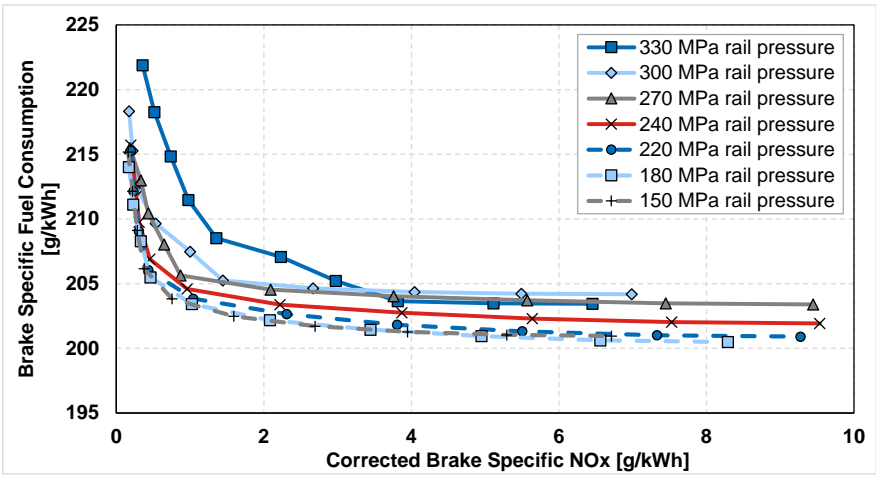

Figure 4: Pareto optimization of $\mathrm{NO}_{\mathrm{x}}$-BSFC trade off with rail pressure at the A50 test condition

Inspection of the optimized parameters from the pareto analysis (figure 5) shows that at ultra-low $\mathrm{NO}_{\mathrm{x}}$ levels the optimal calibration changes above $300 \mathrm{MPa}$ rail pressure from a high EGR strategy to a lower EGR strategy with retarded injection timing. This strategy results in a lower inlet manifold pressure and lower pumping losses and so a lower requirement on the boost system. The reason for the observed reduction in EGR at very high rail pressures is probably due to the shorter injection duration and hence tolerance to more retarded injection without excessive particulate formation during the later phases of the combustion process. CO emissions, as expected increased at retarded injection timings and with increased EGR. HC emissions also increased slightly at higher EGR levels, but generally reduced as the injection timing was retarded to achieve lower $\mathrm{NO}_{\mathrm{x}}$ levels following an inverse trend to the Pm emissions.

From the analysis of the A50 key point, it is clear high rail pressure does not improve the emissions - fuel consumption trade off. High injection pressure inevitably increases the parasitic work required to inject the fuel, and so a material benefit in the efficiency of the combustion must be realized for an overall benefit to be seen. At the A50 condition, the fueling and engine speed are relatively low and so the injection period is not excessively long preventing issues with incomplete combustion at the end of the injection period and high resulting smoke emissions. It is also quite likely the fuel spray will 'over penetrate' at this condition and impinge significantly on the piston bowl as the charge air density is relatively low at this condition compared to higher loads such as C100. These factors together explain why the optimal calibration for minimum fuel consumption was with moderate rail pressure of 150-180MPa. However, the power density of heavy duty engines is likely to continue to rise in the future. The model optimization showed high rail pressures optimized at a calibration with a lower EGR rates, boost pressure and at a retarded injection timing. This calibration may be favorable at higher power densities in minimizing the requirements on the engine boost system and limiting maximum cylinder pressure.
Figure 3: Comparison of model prediction and validation points measured on the single cylinder engine

\section{A50 Test Condition}

A pareto analysis was undertaken to derive a family of $\mathrm{NO}_{\mathrm{x}}$ - BSFC trade of curves at constant rail pressure (figure 4). Euro VI engine out emissions were achieved even at 150MPa rail pressure and the results demonstrate that at this key point, low rail pressure, in the Page 3 of 8 

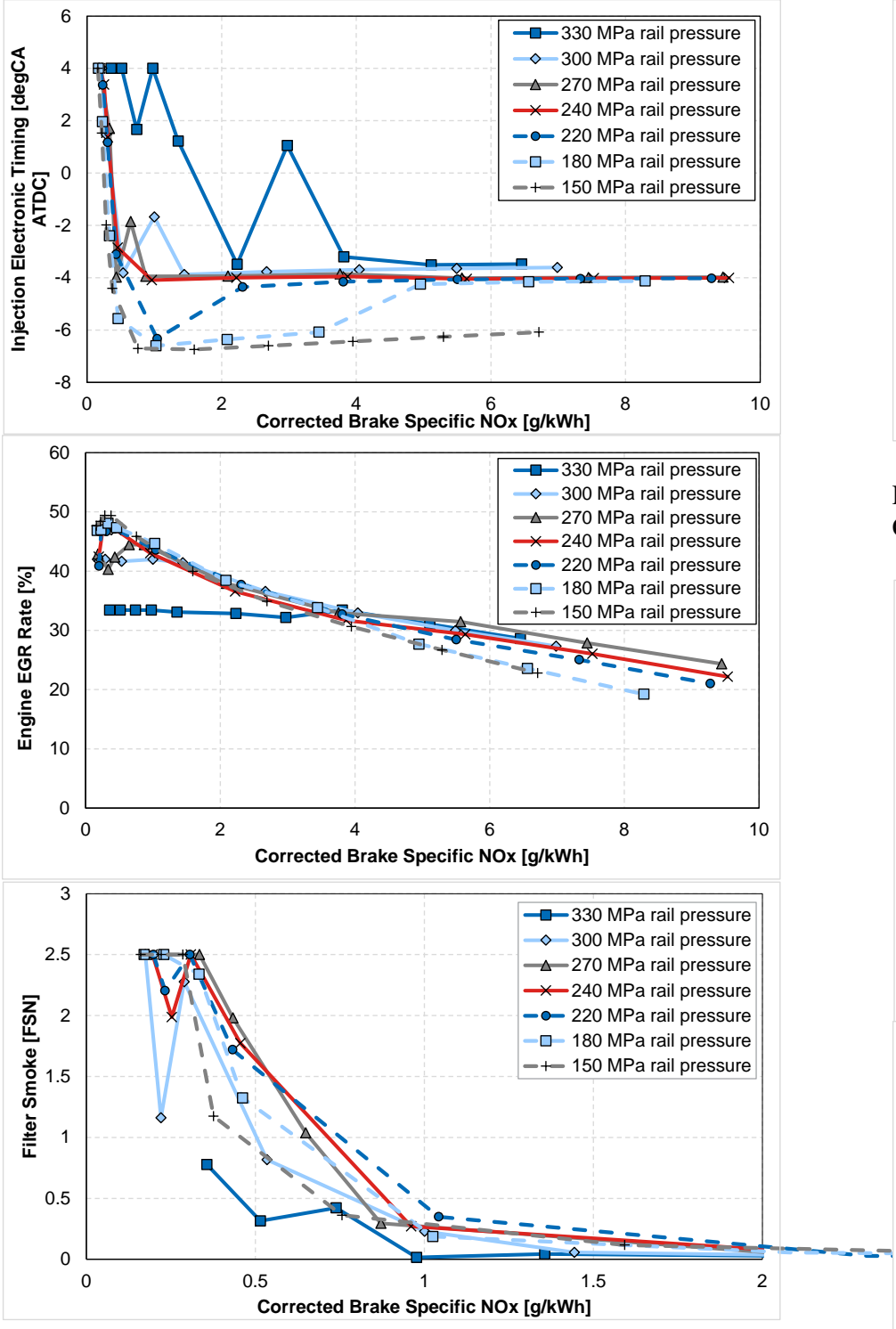

Figure 5: Parameters (electronic injection timing, EGR rate and Filter Smoke) from pareto analysis at A50 test condition

\section{C100 Test Condition}

Unlike with the A50 case rail, pressures of greater than 240MPa were required to achieve less than $0.4 \mathrm{~g} / \mathrm{kWhNO}_{\mathrm{x}}$ within acceptable smoke levels and the $\mathrm{P}_{\max }$ limit of the engine (figure 6). As with the A50 condition, high injection pressures enable a more retarded injection timing within smoke limits due to the shorter injection period and better mixing limiting the cylinder pressure rise (compared to an advanced injection timing strategy) (figure 7). The benefit of high rail pressure in controlling smoke emissions can be clearly seen at $<1 \mathrm{~g} / \mathrm{kWhNO}_{\mathrm{x}}$. Unlike at the A50 condition, high injection pressure will beneficially shorten the injection period reducing the risk of incomplete combustion at high EGR rates and resultant smoke emissions allowing later injection to control $\mathrm{NO}_{\mathrm{x}}$ emissions. This results in a lower EGR requirement and overall improvement in fuel consumption. The charge density is also higher at this condition (compared to A50), reducing the risk of over penetration of the fuel spray at high injection pressures and wetting of the piston wall.

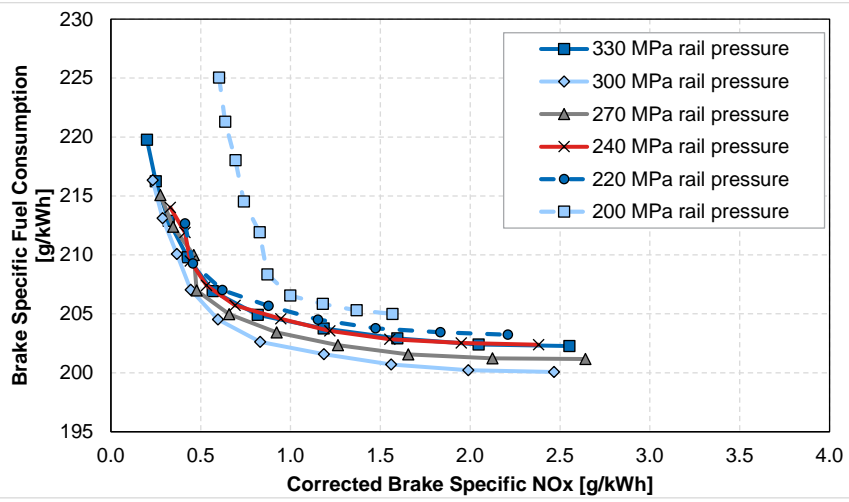

Figure 6: Pareto optimization of $\mathrm{NO}_{\mathrm{x}}$ - BSFC with rail pressure at the C100 test
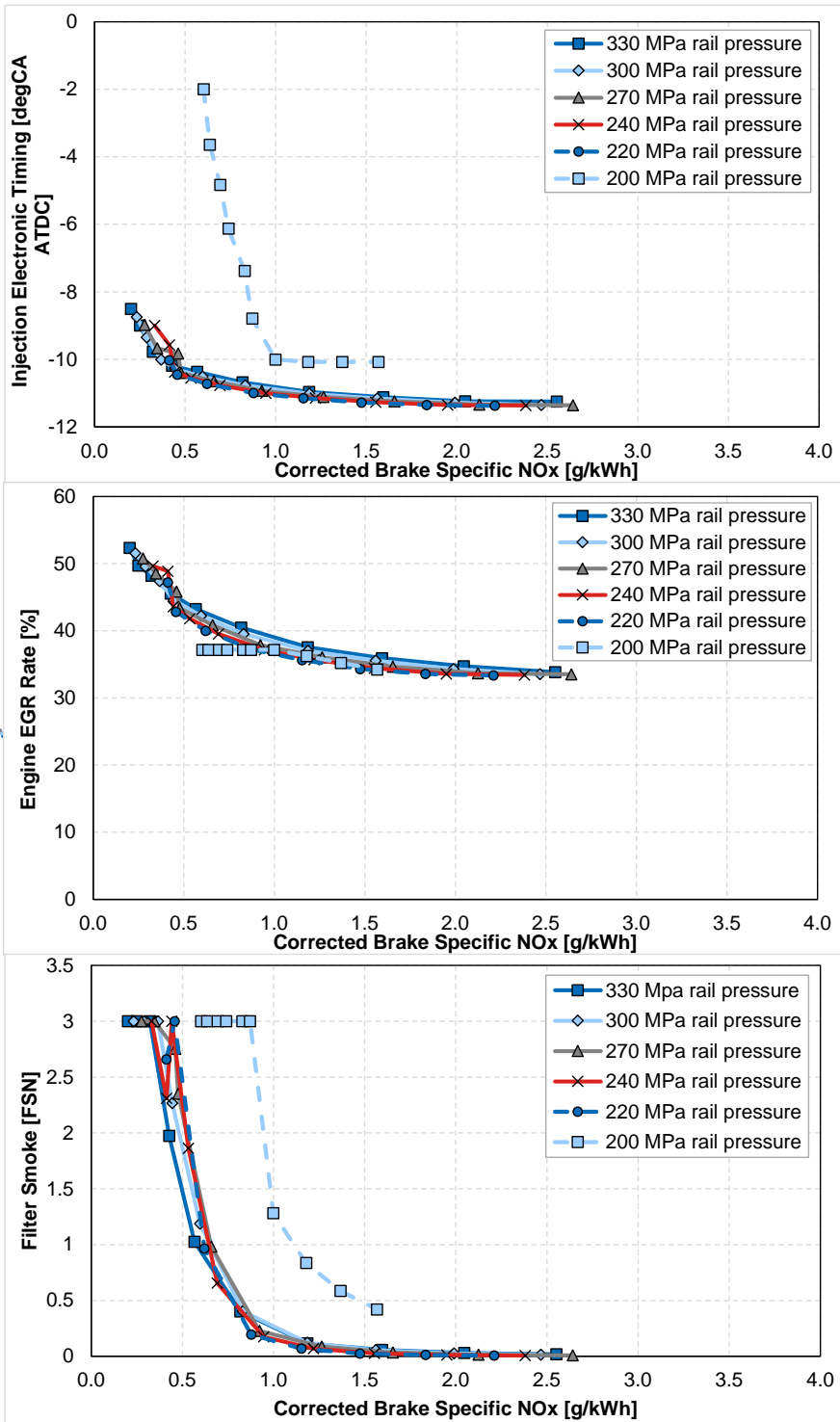

Figure 7: Parameters from pareto analysis at C100 test condition

Further analysis of the optimal engine calibration at higher $\mathrm{NO}_{\mathrm{x}}$ was undertaken, by molding the optimal engine set up at fixed EGR rates. 
The resulting $\mathrm{NO}_{\mathrm{x}}$, and BSFC trade offs are shown in figure 8. The analysis was performed by fixing the EGR rate and optimizing the other parameters for a particular $\mathrm{NO}_{\mathrm{x}}$ target for minimum BSFC at less than $1 \mathrm{FSN}$. A substantial improvement in the trade off is observed when the EGR rate is increased from 20 to 30\%, particularly at $4 \mathrm{~g} / \mathrm{kWhNO}_{\mathrm{x}}$, which is of particular interest for the hybrid EGR - SCR strategy. There is a clear benefit in fuel consumption in operating with EGR at full load due to the more advanced injection timing that can be used to achieve a given $\mathrm{NO}_{\mathrm{x}}$ target with the benefit of EGR for $\mathrm{NO}_{\mathrm{x}}$ control. The corresponding optimal rail pressure is shown in figure 9, which clearly shows the benefit of high rail pressure at moderate ( $>10 \%)$ EGR rates.

High rail pressure is therefore required to achieve very low $\mathrm{NO}_{\mathrm{x}}$ $(<0.4 \mathrm{~g} / \mathrm{kWh})$ levels, mainly due to limitations on maximum cylinder pressure and smoke at the very high EGR rates required to achieve this aggressive $\mathrm{NO}_{\mathrm{x}}$ target. At moderate $\mathrm{NO}_{\mathrm{x}}$ levels $(3-5 \mathrm{~g} / \mathrm{kWh})$, high rail pressure is beneficial at EGR levels of $>30 \%$. The use of higher EGR rates for $\mathrm{NO}_{\mathrm{x}}$ control enables more advanced injection timing and an improved BSFC trade off. The high rail pressure improves mixing and shortens the injection period aiding the control of particulate emissions at the elevated EGR rate.

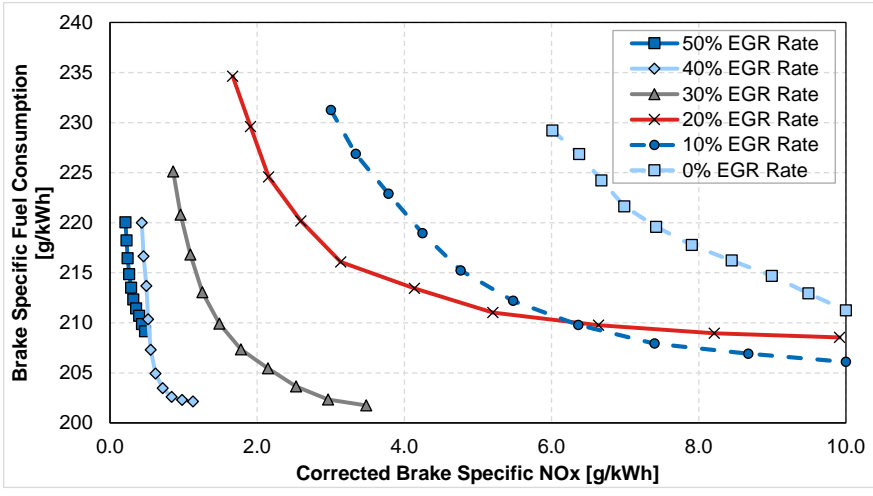

Figure 8: $\mathrm{NO}_{\mathrm{x}}$, and BSFC analysis at fixed EGR rates at C100 condition.

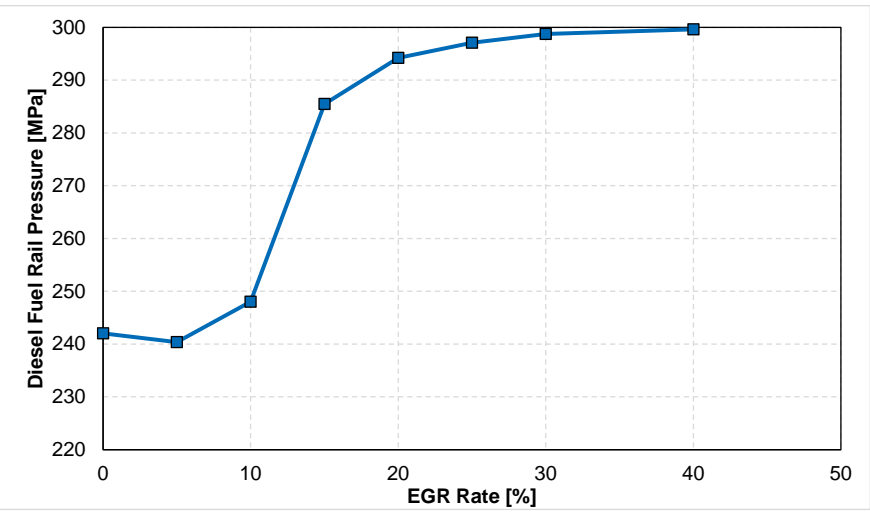

Figure 9: Optimal rail pressure for different EGR rates at C100 condition

\section{Split Injection Study}

A short study was undertaken at the A50 condition to investigate the impact of rail pressure combined with a split fuel injection. The study was undertaken by increasing the separation of two equal injection events and adjusting the injection timing to maintain constant $50 \%$ burn angle up to $1500 \mu$ s separation. Other parameters (EGR, manifold temperature etc.) were held constant. This strategy effectively advances the start of the first injection and retards the end of the second injection as the separation is increased.

The result of the split separation swing, at a fixed EGR rate of $0 \%$, is shown in figure 10 . The selected split injection strategy was observed to increase $\mathrm{NO}_{\mathrm{x}}$ emissions, due to the advance of the first injection as the separation was increased, reduce smoke and improve fuel consumption. The most benefit was observed at low (180MPa) rail pressures consistent with the observations made during the single injection DOE study reported earlier in this paper. The benefit of a shorter pulse width with higher fuel injection pressure still does not provide benefit at the A50 condition. As mentioned previously, it is likely the fuel spray over penetrates at this condition at high rail pressure, offsetting any other benefits.

Further testing was undertaken at 20\% EGR and no appreciable benefit was observed either with splitting the main injection or increasing the rail pressure with a split injection. In this case, the reduced rate of combustion due to EGR will make the combustion process more sensitive to the end of injection timing. The fuel consumption benefit observed in the zero EGR case is, hence not observed with the introduction of EGR.
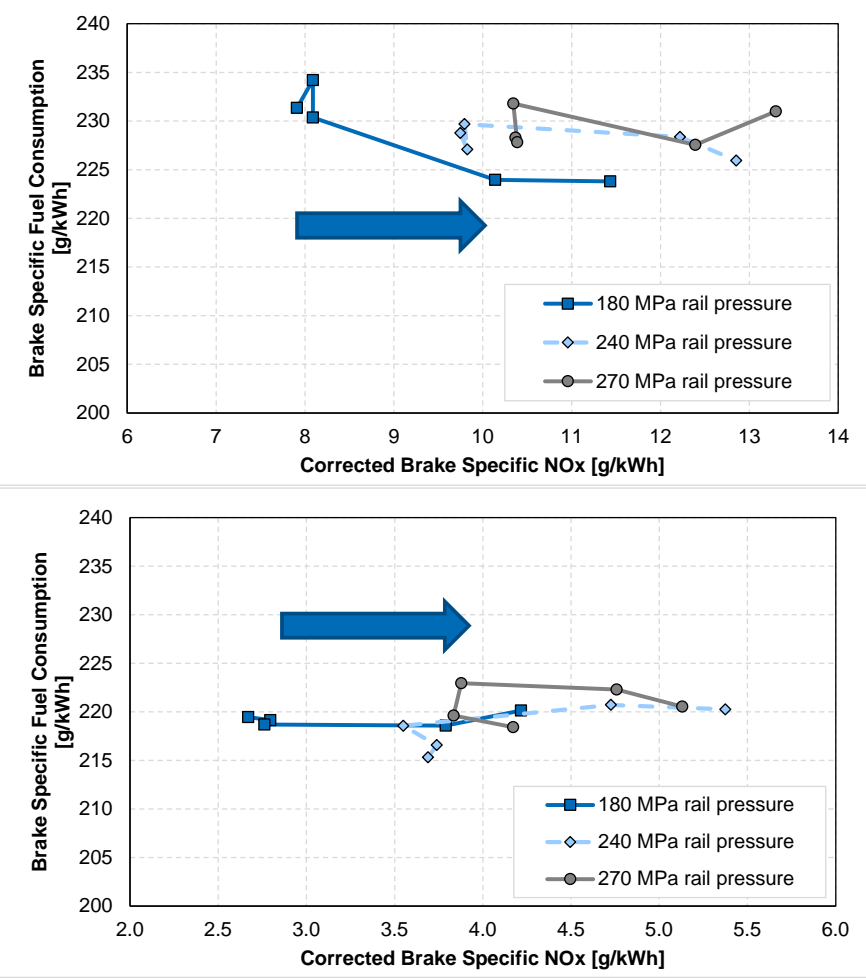

Figure 10: Split injection timing swing at A50 test condition at (a) $0 \%$ EGR and (b) 20\% EGR with increased separation from 0 to $1500 \mu \mathrm{s}$ 
From this short study the strategy of splitting the main injection at constant burn angle has limited benefit at the A50 test condition and in particular high injection pressure is observed to be detrimental to the $\mathrm{NO}_{\mathrm{x}} \mathrm{BSFC}$ trade off. However, others have conducted more detailed studies of the split injection strategy including more injections [6]. Further work is ongoing to investigate the optimal split injection strategy from which the impact of high injection pressure can then be assessed in more detail.

\section{Discussion of Results}

\section{Emissions control with high pressure flexible fuel injection}

The results of the DOE study indicate the optimal fuel injection pressure is very dependent on not only the load point but also the target engine out $\mathrm{NO}_{\mathrm{x}}$ level. This will be determined by the overall emissions control system strategy and the balance between emissions control through in-cylinder measures and aftertreatment, principally through SCR.

At rated power (C100), a strategy biased to very low engine out $\mathrm{NO}_{\mathrm{x}}$ $(<0.4 \mathrm{~g} / \mathrm{kWh}$ ) levels requires high rail pressures of $300 \mathrm{MPa}$ and possibly higher if such equipment becomes available in the future. Analysis, using the DOE method of the optimal engine calibration, showed high rail pressure permitted a more retarded injection timing strategy and lower EGR rates at the low $\mathrm{NO}_{\mathrm{x}}$ levels within acceptable smoke limits. At lower rail pressures, the timing had to be advanced at very high EGR rates to control the end of combustion timing and smoke emissions. This resulted in unacceptably high cylinder pressures and is considered unviable.

At moderate $\mathrm{NO}_{\mathrm{x}}$ levels (3-5g/kWh), target emissions can be achieved at C100 with moderate (150MPa) injection pressures. However, a clear benefit in fuel consumption is observed by increasing the EGR rate to $30 \%$ and increasing the injection pressure to $>270 \mathrm{MPa}$. Again, the high injection pressure shortens the injection period and hence the end of combustion for equivalent injection timing. In the case of moderate NOx levels the timing can be advanced by combining high EGR and injection pressure resulting in a significant improvement in fuel consumption.

At the mid speed mid load cruise condition, (A50), very low engine out $\mathrm{NO}_{\mathrm{x}}$ emissions could be achieved at moderate injection pressures (150MPa). Increasing the rail pressure beyond 180MPa was detrimental to the emissions - fuel consumption trade off and the DOE models optimized at rail pressures in the range of 150-180MPa. Increasing the rail pressure not only impacts the injection of fuel into the cylinder and resulting combustion phasing, but also increases the parasitic work required to deliver fuel to the cylinder. At the lower speed condition, the time available for the combustion process to complete is longer and the benefits of shortening the injection period through high rail pressure are more than offset by the increase in burn rate through mixing (and hence in-cylinder temperatures and $\mathrm{NO}_{\mathrm{x}}$ emissions) and parasitic pumping work on the fuel. It is also likely the fuel spray will over penetrate at high injection pressures at light load conditions.

\section{Total cost of ownership}

It is clear from the experimental program that the benefit of high injection pressure is very dependent on the overall emissions control

Page 6 of 8 strategy. To investigate this further a total cost of ownership (TCO) model was built to study the total fluid (fuel plus Adblue, or more commonly referred to as diesel exhaust fluid, DEF in North America) consumption costs on the target engine out $\mathrm{NO}_{\mathrm{x}}$ emissions and hence combustion strategy. The TCO was calculated using the following formula:

TCO $=$ BSFC $+[($ NOx delta*2.43*(0.83/1.09)*price ratio fraction

The TCO - $\mathrm{NO}_{\mathrm{x}}$ trade off curve is shown in figure 11 for two Adblue costs; $100 \%$ of fuel and $25 \%$ at A50 and C100. This range spans the ranges currently observed in Europe where Adblue is significantly cheaper than the Diesel fuel and North America where fuel costs are generally lower and closer to the price of the Adblue.

Considering first the A50 condition, unsurprisingly, if the Adblue cost is negligible relative to the Diesel cost, a high engine out $\mathrm{NO}_{\mathrm{x}}$ strategy is optimal and a modest rail pressure of $150 \mathrm{MPa}$ is required. At a price ratio of $100 \%$, the optimal strategy shifts to one biased towards more in-cylinder $\mathrm{NO}_{\mathrm{x}}$ control optimizing at $4 \mathrm{~g} / \mathrm{kWh}$ engine out $\mathrm{NO}_{\mathrm{x}}$. It should also be noted that at this condition, the engine is producing effectively no smoke enabling a continuous regeneration strategy of the particulate filter.
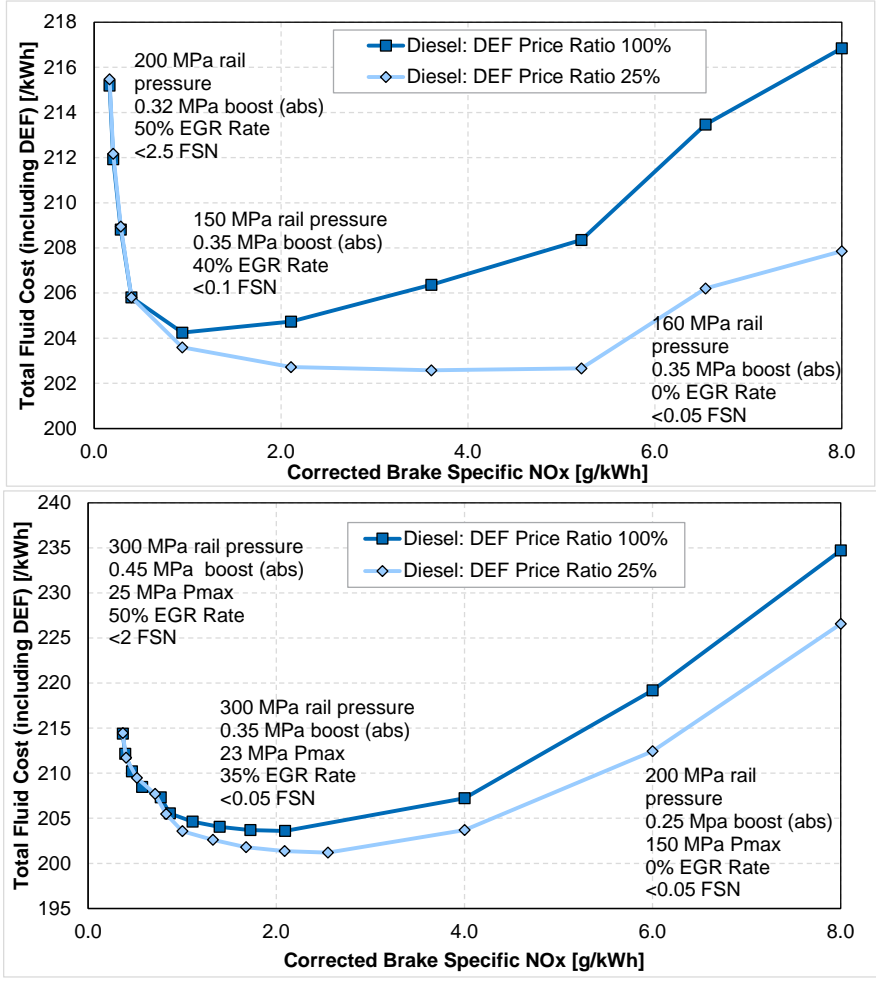

Figure 11: TCO - engine out NOx trade off for different Diesel Adblue price ratios at (a) A50 and (b) C100

At the $\mathrm{C} 100$ condition, even at the $25 \%$ price ratio case, the lowest TCO is at a relatively low engine out $\mathrm{NO}_{\mathrm{x}}$ of around $2 \mathrm{~g} / \mathrm{kWh}$. It is interesting to note many OEMs are adopting a more aggressive aftertreatment strategy and the removal of EGR from the engine. From a TCO viewpoint alone this will not deliver the lowest overall operating cost. However, there are other benefits of removing EGR from the system in simplifying the air handling system (reducing cost) and resulting in a 'cleaner' intake system, potentially beneficial to engine life. The removal of EGR will also reduce vehicle heat 
rejection and allow higher engine ratings within cylinder pressure limits. The overall design choice is therefore complex and depends on capital and maintenance costs as well as operating costs as calculated in this paper. However, the current results do clearly demonstrate there is benefit in a balanced approach between emissions control through in-cylinder and aftertreatment which would favor high injection pressures at high load operating conditions.

\section{Future Trends}

In this section impact of future trends on the requirements of the fuel injection system will be discussed. Future emissions legislation is likely to include limits on greenhouse gas emissions and so there will be increased pressure to improve the thermal efficiency of the base engine. The specific ratings of the engine will also increase as will the trend to downspeed the engine driving up the BMEP levels towards 3MPa BMEP.

To achieve high thermal efficiencies compression ratios are likely to increase, enabled by advanced low friction designs capable of containing the higher peak cylinder pressures. For minimum fuel consumption EGR may be used as a means of controlling engine out $\mathrm{NO}_{\mathrm{x}}$ to $\sim 8 \mathrm{~g} / \mathrm{kWh}$ in combination with high efficiency SCR. These factors, combined with the trend of increased power density, is likely to push maximum cylinder pressures to $25 \mathrm{MPa}$ or higher. To achieve higher power output and optimal efficiency with a combined EGR-

SCR strategy the research reported here showed clear benefit in high injection pressures at high load (C100) conditions. As such, rail pressures are likely to increase to $280 \mathrm{MPa}$ or higher. High rail pressures, combined with EGR, enable a more retarded injection strategy to be used limiting the cylinder pressure at high load conditions.

The research reported here showed limited benefit of a simple split injection strategy. However, the use of multiple injections as a means of rate shaping and controlling initial burn and rate of heat release (RoHR) should not be discounted.

The trend of increasing BMEP will eventually require the adoption of two stage turbocharging to supply sufficient air to the engine at high load conditions. The DOE study showed high injection pressures reduced the air requirements on the engine. As BMEP levels increase higher injection pressures could be used to reduce the requirements on the engine boosting system.

\section{Conclusions}

A comprehensive Design of Experiments program was undertaken to investigate the benefit of high injection pressure at Euro VI emissions levels. Three strategies were considered; in-cylinder $\mathrm{NO}_{\mathrm{x}}$ control alone through the use of high levels of EGR, combined EGR and SCR and SCR alone. Two key points were studied; high load high speed (C100) and a low speed mid load condition (A50).

At the C100 condition high injection pressures in excess of 240MPa are required to achieve engine out $\mathrm{NO}_{\mathrm{x}}$ conditions within smoke and Pmax limitations. High injection pressures were also beneficial at the combined EGR and SCR strategy, by enabling higher EGR rates and more advanced injection timings, improving the fuel consumption $\mathrm{NO}_{\mathrm{x}}$ trade off.

Page 7 of 8
At the A50 condition, ultra low $\mathrm{NO}_{\mathrm{x}}$ levels could be achieved with modest (150MPa) injection pressures and high injection pressures were found to be detrimental to the $\mathrm{NO}_{\mathrm{x}}$ fuel consumption trade off, probably due to increased parasitic work to pressurize the fuel and over penetration of the fuel spray.

A short split injection strategy study was also undertaken at the A50 condition. The separation between two injection events was progressively increased whilst maintaining the $50 \%$ burn angle. Increased separation of the injection events was found in all cases to increase $\mathrm{NO}_{\mathrm{x}}$ emissions. In the no EGR case the fuel consumption was also improved due to the benefit of more advanced injection timing and hence optimal combustion phasing for fuel economy. Higher rail pressures were found to be detrimental to the emissionsfuel consumption trade off, as observed in the single injection study. Further testing with EGR showed no benefit in fuel consumption, probably due to the end of combustion being two retarded as the second injection was retarded. Although these results showed little benefit of split injection, particularly at high rail pressures, further work is required to explore the complex trade off with split and multiple injections and is the subject of future work.

Considering future trends pressure to increase both power density and thermal efficiency will benefit from high injection pressures, in particular at high engine loads in the future. We therefore conclude the current trend of increased injection pressure is likely to continue for the foreseeable future.

\section{References}

[1] Stanton, D., "Systematic Development of Highly Efficient and Clean Engines to Meet Future Commercial Vehicle Greenhouse Gas Regulations," SAE Int. J. Engines 6(3):1395-1480, 2013, doi:10.4271/2013-01-2421

[2] Graham, M., Crossley, S., Harcombe, T., Keeler, N. et al., "Beyond Euro VI - Development of A Next Generation Fuel Injector for Commercial Vehicles," SAE Technical Paper 201401-1435, 2014, doi:10.4271/2014-01-1435.

[3] Wloka, J., Pflaum, S., and Wachtmeister, G., "Potential and Challenges of a 3000 Bar Common-Rail Injection System Considering Engine Behavior and Emission Level," SAE Int. J. Engines 3(1):801-813, 2010, doi:10.4271/2010-01-1131.

[4] Schuckert, M. "Improved vehicle fuel affiance for further emissions reduction”. $10^{\text {th }}$ Integer Emissions Summit. Dusseldorf $18^{\text {th }}$ July 2014

[5] Schreier, H., Lukas, W., Theissl, H. \& Decker, M. "Potentials and challenges for next generation HD diesel engines”. SAE Heavy Duty Diesel Emissions Control Symposium. September 17-18 2014 Gothenburg, Sweden

[6] Chapman, K., De Bruijn, M., Dransfield, L. \& Goold, R. “Heavy duty fuel systems: Developing the next generation. Fuel systems for IC engines. IMechE, London 10-11 March 2015.

[7] Johnson, J., Naber, J., Lee, S., Hunter, G. et al., "Correlations of Non-Vaporizing Spray Penetration for 3000 MPa Diesel Spray Injection," SAE Technical Paper 2013-24-0033, 2013, doi:10.4271/2013-24-0033. 
[8] Meek, G., Williams, R., Thornton, D., Knapp, P. et al., "F2E Ultra High Pressure Distributed Pump Common Rail System," SAE Technical Paper 2014-01-1440, 2014, doi:10.4271/201401-1440.

[9] Sushma, Y., Sridhar, M., and Dharmadhikari, A., "Experiments Planning for Robust Design through CAE," SAE Technical Paper 2006-01-3518, 2006, doi:10.4271/2006-01-3518.

\section{Acknowledgments}

The authors would also like to thank Delphi Diesel Systems for providing the F2E hardware and invaluable support through the project. Finally, we would like to thank the directors of Ricardo for permission to publish the results of this project.

\section{Abbreviations}

\begin{tabular}{ll} 
BMEP & $\begin{array}{l}\text { Brake Mean Effective } \\
\text { Pressure }\end{array}$ \\
BSFC & $\begin{array}{l}\text { Break Specific Fuel } \\
\text { Consumption }\end{array}$ \\
DOE & Design of Experiments \\
EGR & Exhaust Gas Recirculation \\
FSN & Filter Smoke Number \\
HC & Hydrocarbon emissions \\
NO & Oxides of nitrogen emissions \\
Pm & Particulate mass emissions \\
RoHR & Rate of Heat Release \\
SCR & Selective Catalytic \\
TCO & Reduction \\
SCRE & Single Cylinder Research \\
& Engine \\
& Total Cost of Ownership. \\
\hline
\end{tabular}

